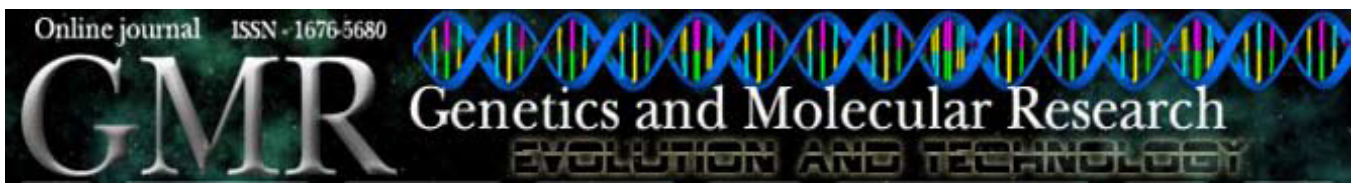

\title{
Genetic parameters for productive life traits and reproductive efficiency traits at 6 years in Nellore cattle
}

\author{
J.C.C. Balieiro, J.P. Eler, J.B.S. Ferraz, E.C. Mattos and C.C. Balieiro \\ Grupo de Melhoramento Animal e Biotecnologia, \\ Faculdade de Zootecnia e Engenharia de Alimentos, \\ Universidade de São Paulo, Pirassununga, SP, Brasil \\ Corresponding author: J.C.C. Balieiro \\ E-mail: balieiro@usp.br
}

Genet. Mol. Res. 7 (4): 1312-1318 (2008)

Received October 20, 2008

Accepted October 21, 2008

Published November 18, 2008

\begin{abstract}
The objective of the present study was to estimate (co)variance components for length of productive life (LPL) and some alternative reproductive traits of 6-year-old Nellore cattle. The data set contained 57,410 records for age at first calving from Nellore females and was edited to remove animal records with uncertain paternity and cows with just one piece of calving information. Only animals with age at first calving ranging from 23 to 48 months and calving intervals between 11 and 24 months were kept for analysis. LPL and life production (LP) were used to describe productive life. LPL was defined as the number of months a cow was kept in the herd until she was 6 years old, given that she was alive at first calving and LP was defined as total number of calves in that time. Four traits were used to describe reproductive traits: two breeding efficiencies on original scale were estimated using Wilcox and Tomar functions (BEW and BET, respectively), and two breeding efficiencies transformed (ASBEW and ASBET, respectively), using the function [arcsine (square root $(\mathrm{BE} i / 100))$ ]. Estimates of heritability for measures of LPL and LP were low and ranged from 0.04 to 0.05 . Estimates of heritability for breeding efficiencies on original and transformed
\end{abstract}


scales oscillated from 0.18 to 0.32 . Estimates of genetic correlations ranged from -0.57 to 0.79 for LPL and other traits and from 0.28 to 0.63 for LP and other traits.

Key words: Breeding efficiency; Longevity; Selection; Beef cattle

\section{INTRODUCTION}

Length of productive life (LPL) and reproductive traits of a cow are complex traits that affect directly the profitability and the efficiency of production systems. Martinez et al. (2004) reported that longer productive life may increase profits by: decreasing annual cost of replacements of cow, increasing herd production through an increase in the proportion of cows in higher-producing age groups, decreasing the number of replacements to be reared, and increasing voluntary culling. Improvements in reproductive indexes represent another way of decreasing costs and increasing net income. In beef cattle, reproductive performance is a major component in culling decisions, and several traits have been suggested to evalute reproductive efficiency. Some reproductive traits have been proposed to access the age at first calving (AFC) and reproductive efficiency, which had pointed to low heritability. Doyle et al. (1996) and Evans et al. (1999) evaluated heifer pregnancy, defined as the probability of a heifer being pregnant after the end of the breeding season when she is exposed to a bull or inseminated. In Brazil, Eler et al. (2002, 2004, and 2006) reported a high heritability for heifer pregnancy, using single-trait and two-trait animal models, respectively. These authors analyzed pregnancy records of Nellore heifers exposed to breeding at about 14 months of age. Stayability was used as an indicator of reproductive performance in Canadian Holsteins by Van Doormaal et al. (1985) and in purebred Angus by Snelling et al. (1995). Martinez et al. (2005) studied Hereford cows, using a single-trait generalized linear mixed model for a threshold trait and a linear mixed model without transformation of the records. These authors reported heritability for the threshold model, linear model and linear model transformed to underlying normal scale ranging from 0.17 to 0.23 , from 0.09 to 0.19 , and from 0.09 to 0.35 , respectively, for stayability to specific ages. Recently, Van Melis et al. (2007), using nonlinear single-trait analysis of stayability in Nellore cows at 5,6 and 7 years, found heritability estimates of $0.25,0.22$, and 0.28 , respectively.

The objective of the present study was to estimate (co)variance components of LPL and some alternative reproductive efficiency traits of 6-year-old Nellore cattle.

\section{MATERIAL AND METHODS}

\section{Data description}

The data came from Agro-Pecuária CFM Ltda., located in northeast São Paulo State and western Mato Grosso do Sul, Brazil. Agro-Pecuária CFM is a Nellore cattle operation consisting of close to 17,000 Nellore cows. This company sells around 2000 young Nellore replacement bulls of approximately 7000 weaned calves per year. Both bulls and heifers were maintained on high-quality pasture (40\% Brachiaria brizantha, 50\% Panicum maximum, and $10 \%$ others) and provided only salt and mineral supplementation. The data used were from animals born from late August to December and that remained with their dams until 7 months of age on high-quality pasture. From 1984 until 1995, the heifers were first exposed to breeding 
at the age of approximately 24 months. From 1995/1996, the heifers started to be first exposed to reproduction at the age of 14 months. The heifers that did not conceive at this first exposure were given another chance at the age of 24 months. A short breeding season of 60 days for cows and 90 days for heifers has always been adopted. The ratio of cows per bull was about 35:1.

\section{Traits analyzed}

The initial data set included 57,410 AFC records from females born from 1981 through 2002 and was edited to remove records of animals with uncertain paternity and cows with just one piece of calving information. Only animals with AFC ranging from 23 to 48 months and calving intervals between 11 and 24 months were kept for analysis.

Two traits were used to describe productive life. LPL was defined as the number of months a cow survived in 6 years, given that she was alive at first calving. Life production (LP) was defined as total number of calves.

Four traits were used to describe reproductive efficiency traits: two breeding efficiencies on original scale were estimated using Wilcox et al. (1957) and Tomar (1965) functions (BEW and BET), and two breeding efficiencies transformed (ASBEW and ASBET) using the function [arcsine (square root (BEi/100))]. Wilcox et al. (1957) and Tomar (1965) functions are described below,

$$
B E W=\frac{335 \times(n-1)}{D} \times 100 \text { (Wilcox et al., 1957) }
$$

where, $335=$ ideal calving intervals; $n=$ total number of calvings; $D=$ number of days from first calving until last calving, given that stay up to 6 years old (72 months) in the herd.

$$
B E T=\frac{n \times 335+945}{A F C+S C I} \times 100 \quad(\text { Tomar, 1965) }
$$

where, $n=$ number of calving intervals; $945=$ ideal age at first calving, in days; $A F C=$ real $\mathrm{AFC}$, in days; $S C I=$ real sum of calving intervals, in days.

\section{Statistical analyses}

(Co)variance components and genetic parameters for productive life (LPL and LP) and reproductive efficiency traits (BEW, BET, ASBEW and ASBET) were estimated by restricted maximum likelihood using a two-trait animal model. For all traits, the model included the contemporary group as a fixed effect, and animal direct genetic and residual effects as random. The contemporary group was defined as cows born in the same herd-year. The two-trait animal model was as follows:

$$
\left[\begin{array}{l}
y_{1} \\
y_{2}
\end{array}\right]=\left[\begin{array}{cc}
X_{1} & 0 \\
0 & X_{2}
\end{array}\right]\left[\begin{array}{l}
b_{1} \\
b_{2}
\end{array}\right]+\left[\begin{array}{cc}
Z_{1} & 0 \\
0 & Z_{2}
\end{array}\right]\left[\begin{array}{l}
u_{1} \\
u_{2}
\end{array}\right]+\left[\begin{array}{l}
e_{1} \\
e_{2}
\end{array}\right]
$$

where $\mathrm{y}_{1}=$ an $\mathrm{n}_{1} \times 1$ vector of observations for trait $1 ; \mathrm{y}_{2}=$ an $\mathrm{n}_{2} \times 1$ vector of observations for trait $2 ; b_{1}=a$ vector of fixed effects for trait $1 ; b_{2}=a$ vector of fixed effects for trait $2 ; u_{1}=a$ vector of random animal direct genetic values for trait $1 ; \mathrm{u}_{2}=$ a vector of random animal direct 
genetic values for trait $2 ; e_{1}=$ an $n_{1} \times 1$ vector of random residual effects for trait $1 ; e_{2}=$ an $n_{2}$ $\times 1$ vector of random residual effects for trait 2 , and $X, Z=$ known incidence matrices relating the observations to fixed and random effects, respectively.

The first and second moments of the model are assumed to be:

$$
\mathrm{E}\left[\begin{array}{c}
y_{1} \\
y_{2} \\
u_{1} \\
u_{2} \\
e_{1} \\
e_{2}
\end{array}\right]=\left[\begin{array}{c}
X_{1} b_{1} \\
X_{2} b_{2} \\
0 \\
0 \\
0 \\
0
\end{array}\right] \text { and } \operatorname{Var}\left[\begin{array}{c}
u_{1} \\
u_{2} \\
e_{1} \\
e_{2}
\end{array}\right]=\left[\begin{array}{cc}
G_{0} \otimes A & 0 \\
0 & R_{e}
\end{array}\right]
$$

where A = Wright's numerator relationship matrix;

$$
G_{0}=\left[\begin{array}{cc}
\sigma_{u 1}^{2} & \sigma_{u 1 u 2} \\
\sigma_{u 1 u 2} & \sigma_{u 2}^{2}
\end{array}\right]
$$

$\sigma_{u 1}^{2}=$ additive genetic variance for trait $1 ; \sigma^{2}{ }_{u 2}=$ additive genetic variance for trait $2 ; \sigma_{u l u 2}=$ additive genetic covariance between trait 1 and trait 2 ;

$$
R_{e}=\left[\begin{array}{ccc}
\sigma_{e 1}^{2} I_{1} & 0 & 0 \\
0 & R_{0} \otimes I_{2} & 0 \\
& & \sigma_{e 2}^{2} I_{3}
\end{array}\right] \text { and } R_{0}=\left[\begin{array}{cc}
\sigma_{e 1}^{2} & \sigma_{e l e 2} \\
\sigma_{e 1 e 2} & \sigma_{e 2}^{2}
\end{array}\right] \quad \text { (Equation 4) }
$$

$\sigma_{e l}^{2}=$ residual variance for trait $1 ; \sigma_{e 2}^{2}=$ residual variance for trait $2 ; \sigma_{e l e 2}=$ residual covariance between traits 1 and 2; $I_{1}=$ an identity matrix with order, number of animals with records only for trait $1 ; I_{2}=$ an identity matrix with order, number of animals with records for both traits; $I_{3}$ $=$ an identity matrix with order, number of animals with records only for trait 2 . For pairwise analyses with no missing values (e.g., BEW with ASBEW, BET, and ASBET $\left.\left[n_{l}=n_{2}\right]\right), I_{l}$ and $I_{3}$ will collapse into $I_{2}$ (i.e., $R_{e}=R_{0} \otimes I_{2}$ ).

The MTDFREML software (Boldman et al., 1995) was used, and pedigree data included 25,390 animals with an observation on LPL or BEW/BET plus all known relationships up to nine generations. The simplex algorithm was stopped when the variance of the function values (i.e., $2 \log \mathrm{L}$ with $\mathrm{L}=$ likelihood given $y$ ) in the simplex was less than $1 \times 10$. Once the convergence criterion was reached, fresh restarts from those estimates were continued until $2 \log L$ differed by less than $1 \times 10^{-6}$ between successive restarts.

\section{RESULTS AND DISCUSSION}

Table 1 summarizes the number of observations and descriptive statistics for productive life and reproductive efficiency traits. Estimates in means \pm SD for Herefords by Martinez et al. (2004) were 29.39 \pm 11.51 and $37.87 \pm 15.62$ months from LPL at 3 and 4 years after first calving, respectively. Similar to this study, Caraviello et al. (2004) reported, in Holsteins from the East North Central region of the U.S., 21.6 and 24.7 months for longevity, in failure and 
censored records, respectively. The estimate of LP by Martinez et al. (2004) was $3.72 \pm 2.07$ calves born in 6 years after first calving.

Table 1. Number of observations (N) and unadjusted mean (Mean), standard deviation (SD), coefficient of
variation (CV\%), and minimum and maximum for evaluated traits.
\begin{tabular}{lccrrrr}
\hline Trait & $\mathrm{N}$ & Mean & SD & CV (\%) & Minimum & Maximum \\
\hline LPL & 8996 & 21.16 & 9.41 & 44.44 & 10.00 & 72.0 \\
LP & 8996 & 2.45 & 0.61 & 25.02 & 2.00 & 5.0 \\
BEW & 8882 & 78.94 & 14.43 & 18.23 & 15.28 & 100.0 \\
BET & 8882 & 86.59 & 6.01 & 6.94 & 58.08 & 100.0 \\
ASBEW & 8882 & 63.92 & 10.26 & 16.05 & 23.01 & 90.0 \\
ASBET & 8882 & 69.51 & 6.85 & 9.85 & 49.65 & 90.0 \\
\hline
\end{tabular}

$\mathrm{LPL}=$ length of productive life; $\mathrm{LP}=$ life production defined as total number of calves; $\mathrm{BEW}=$ breeding efficiency on original scale estimated using the Wilcox et al. (1957) function; BET = breeding efficiency on original scale estimated using the Tomar (1965) function; ASBEW = breeding efficiency transformed scale using the Wilcox et al. (1957); ASBET = breeding efficiency transformed scale using the Tomar (1965).

Table 2 summarizes the estimates of additive genetic and residual variance components and genetic parameters for productive and reproductive efficiency traits.

Table 2. Estimates of additive genetic and residual variance components and genetic parameters from two-trait animal models for productive and reproductive efficiency traits in Nellore beef cattle.

\begin{tabular}{|c|c|c|c|c|c|c|c|}
\hline Trait $i \times j$ & $\hat{\sigma}_{a_{i}}^{2}$ & $\hat{\sigma}_{a_{j}}^{2}$ & $\hat{\sigma}_{e_{i}}^{2}$ & $\hat{\sigma}_{e_{j}}^{2}$ & $\hat{h}_{i}^{2}$ & $\hat{h}_{j}^{2}$ & $\hat{r}_{a_{i j}}^{2}$ \\
\hline LPL $x$ LP & 3.24 & 0.01 & 75.96 & 0.32 & 0.04 & 0.04 & 0.79 \\
\hline LPL $x$ BEW & 3.65 & 47.23 & 75.62 & 152.62 & 0.05 & 0.24 & -0.57 \\
\hline LPL x BET & 2.81 & 6.48 & 76.33 & 25.03 & 0.04 & 0.21 & 0.29 \\
\hline LPL x ASBEW & 3.61 & 23.61 & 75.65 & 78.21 & 0.05 & 0.23 & -0.52 \\
\hline LPL x ASBET & 2.81 & 6.48 & 76.33 & 25.03 & 0.04 & 0.21 & 0.29 \\
\hline LP x BEW & 0.01 & 48.49 & 0.32 & 148.41 & 0.05 & 0.25 & 0.28 \\
\hline LP x BET & 0.01 & 6.83 & 0.32 & 24.72 & 0.04 & 0.22 & 0.51 \\
\hline LP x ASBEW & 0.01 & 24.26 & 0.32 & 76.11 & 0.05 & 0.24 & 0.32 \\
\hline LP x ASBET & 0.01 & 4.48 & 0.32 & 35.93 & 0.04 & 0.11 & 0.63 \\
\hline BEW x BET & 46.97 & 6.55 & 149.57 & 24.92 & 0.24 & 0.21 & 0.35 \\
\hline BEW x ASBEW & 47.61 & 23.68 & 149.18 & 76.60 & 0.24 & 0.24 & 1.00 \\
\hline BET $\times$ ASBET & 10.26 & 7.32 & 22.04 & 33.69 & 0.32 & 0.18 & 0.96 \\
\hline
\end{tabular}

Abbreviations for traits are given in Table 1. $\hat{\sigma}_{a}^{2}=$ estimate of additive genetic variance for trait $i ; \hat{\sigma}_{a}^{2}=$ estimate of additive genetic variance for trait $j ; \hat{\sigma}_{e_{i}}^{2}=$ estimate of residual variance for trait $i$; $\hat{\sigma}_{e_{j}}^{2}=$ estimate of residual variance for trait $j ; \hat{h}_{i}^{2}=$ estimate of heritability for trait $i ; \hat{h}_{j}^{2}=$ estimate of heritability for trait $j ; \hat{r}_{a_{i j}}^{2}=$ estimate of genetic correlation.

Estimates of heritability for measures of LPL and LP were low and ranged from 0.04 to 0.05 . Estimates of heritability for LPL were similar to those found by Martinez et al. (2004) in Hereford cattle, who reported 0.05 to 0.15 for 6 distinct LPL. Van Doormaal et al. (1985) found LPL heritability estimates ranging between 0.04 and 0.06 in Canadian Holsteins. Estimates of genetic correlations were in the range of -0.57 to 0.79 for LPL and other traits. High genetic correlation for analysis LPL x LP was similar to that reported by Martinez et al. (2004). High genetic correlation for analyses LPL x BEW and LPL x ASBEW suggest some antagonism between productive and these reproductive efficiency traits as already observed in dairy cattle (Balieiro et al., 2003; Tsuruta et al., 2005). 
Estimates of heritability for LP were lower than those reported by Martinez et al. (2004) who found values of 0.16 to 0.17 . The genetic correlations for LP and other traits (Table 2), ranged from 0.28 (between LP x BEW) to 0.63 (between LP x ASBET). These estimates indicate synergism between this productive trait and the breeding efficiencies.

Estimates of heritability for reproductive efficiency traits on original and transformed scales oscillated from 0.18 to 0.32 , respectively. Unfortunately, other estimates of heritability for breeding efficiencies are not available for comparison. Thus, these heritability values are similar to those reported for many other reproductive traits in dairy and beef cattle. Martinez et al. (2005) reported that estimates of heritability ranged from low $(0.09 \pm 0.08)$ for stayability at 3 years, to moderate $(0.30 \pm 0.14)$ for stayability at 6 years, with the threshold model. Similarly, these authors found estimates of heritability ranging from $0.05 \pm 0.04$, for stayability at 3 years, to $0.15 \pm 0.07$ for stayability at 6 years when using a linear model with binomial observations. Estimates of heritability transformed to an underlying normal scale were in close agreement with those from the threshold model, ranging from low $(0.09)$ for stayability at 3 years to moderate $(0.35)$ for stayability at 6 years. For BEW and BET, the results found were close to those observed by Van Melis et al. (2007) who reported heritability for stayability in Nellore cows at 5, 6 and 7 years varying from 0.22 to 0.28 . Ducrocq et al. (1988) suggest that nonlinear approaches may have a better ability to detect genetic variation in binary reproductive traits than linear methods. Genetic variation has been detected by linear models for the breeding efficiency traits proposed by Wilcox et al. (1957) and Tomar (1965).

Estimates of genetic correlations between breeding efficiencies on original and transformed scales (1.00 for BEW x ASBEW and 0.96 for BET x ASBET) suggest that there will be little or no effect on top bulls when selection is based on an original or transformed scale.

\section{CONCLUSION}

Selection for LPL, defined as the number of days a cow survived in 6 years, given the opportunity to be alive at first calving, and for LP, defined as total number of calves, would be possible, but the response to selection is expected to be slow due to low estimates of heritability. The estimates of heritability obtained for BEW and BET suggest that the use of expected progeny differences on these traits can improve breeding efficiency in the Nellore breed. In this case, expected progeny differences for BEW and BET can be obtained by linear models.

\section{ACKNOWLEDGMENTS}

Research supported by FAPESP, CNPq and Agro-Pecuária CFM Ltda., Brazil.

\section{REFERENCES}

Balieiro ES, Pereira JCC, Verneque RS, Balieiro JC, et al. (2003). Estimates of heritability and genetic relationship between some reproductive traits and milk yield in Gyr cattle. Arq. Bras. Med. Vet. Zootec. 55: 85-91.

Boldman KG, Kriese LA, Van Vleck LD and Kachman SD (1995). A Set of Program to Obtain Estimates of Variances and Covariances: A Manual for Use of MTDFREML. ARS-USDA (Agricultural Research Service - United States Department of Agriculture), Clay Center.

Caraviello DZ, Weigel KA and Gianola D (2004). Prediction of longevity breeding values for US Holstein sires using survival analysis methodology. J. Dairy Sci. 87 (Suppl 1): 3518-3525.

Doyle SP, Green RD, Golden BL, Mathiews GL, et al. (1996). Genetic parameter estimates for heifer pregnancy rate and 
subsequent rebreeding rate in Angus cattle. J. Anim. Sci. 74 (Suppl 1): 117 (Abstract).

Ducrocq V, Quaas RL, Pollak EJ and Casella G (1988). Length of productive life of dairy cows. 2. Variance component estimation and sire evaluation. J. Dairy Sci. 71: 3071-3079.

Eler JP, Silva JA, Ferraz JB, Dias F, et al. (2002). Genetic evaluation of the probability of pregnancy at 14 months for Nellore heifers. J. Anim. Sci. 80: 951-954.

Eler JP, Silva JA, Evans JL, Ferraz JB, et al. (2004). Additive genetic relationships between heifer pregnancy and scrotal circumference in Nellore cattle. J. Anim. Sci. 82: 2519-2527.

Eler JP, Ferraz JB, Balieiro JC, Mattos EC, et al. (2006). Genetic correlation between heifer pregnancy and scrotal circumference measured at 15 and 18 months of age in Nellore cattle. Genet. Mol. Res. 5: 569-580.

Evans JL, Golden BL, Bourdon RM and Long KL (1999). Additive genetic relationships between heifer pregnancy and scrotal circumference in Hereford cattle. J. Anim. Sci. 77: 2621-2628.

Martinez GE, Koch RM, Cundiff LV, Gregory KE, et al. (2004). Genetic parameters for six measures of length of productive life and three measures of lifetime production by 6 yr after first calving for Hereford cows. J. Anim. Sci. 82: 1912-1918.

Martinez GE, Koch RM, Cundiff LV, Gregory KE, et al. (2005). Genetic parameters for stayability, stayability at calving, and stayability at weaning to specified ages for Hereford cows. J. Anim. Sci. 83: 2033-2042.

Snelling WM, Golden BL and Bourdon RM (1995). Within-herd genetic analyses of stayability of beef females. J. Anim. Sci. 73: 993-1001.

Tomar NS (1965). A note on the method of working out breeding efficiency in Zebu cows and buffaloes. Indian Dairyman 17: 389-390.

Tsuruta S, Misztal I and Lawlor TJ (2005). Changing definition of productive life in US Holsteins: effect on genetic correlations. J. Dairy Sci. 88: 1156-1165.

Van Doormaal BJ, Schaeffer LR and Kennedy BW (1985). Estimation of genetic parameters for stayability in Canadian Holsteins. J. Dairy Sci. 68: 1763-1769.

Van Melis MH, Eler JP, Oliveira HN, Rosa GJ, et al. (2007). Study of stayability in Nellore cows using a threshold model. J. Anim. Sci. 85: 1780-1786.

Wilcox CJ, Pfau KO and Bartlett JW (1957). An investigation of the inheritance of female reproductive performance and longevity, and their interrelationships within a Holstein-Friesian herd. J. Dairy Sci. 40: 942-947. 